\title{
An Analysis of Emergency Healthcare Delivery in Ghana: Lessons from Ambulance and Emergency Services in Bibiani Anhwiaso Bekwai District
}

\author{
Ronald Adamtey \\ Department of Planning \\ Kwame Nkrumah University of Science and Technology, Kumasi, Ghana \\ Email:radamtey.cap@knust.edu.gh \\ Josephine Frimpong \\ Department of Planning \\ Kwame Nkrumah University of Science and Technology, Kumasi, Ghana \\ Email: josephinefrimpong910@yahoo.com \\ and \\ Romanus D. Dinye \\ Centre for Settlements Studies \\ Kwame Nkrumah University of Science and Technology, Kumasi, Ghana \\ Email: $\underline{\text { dddinye.cap@knust.edu.gh }}$ \\ DOI//http://dx.doi.org/10.4314/gjdsv12i1\&2.5
}

\begin{abstract}
This paper explores the benefits of planning a reliable and effective ambulance and emergency service towards healthcare delivery at the District level in Ghana. It addresses the question of what should be the focus of such planning. A case study research design was adopted by employing detailed qualitative interviews with health staff, operators of ambulance services, police officers, victims of accident and emergency and private transport operators in the BibianiAnhwiaso-Bekwai District. The study found that ambulance and emergency services were not effective and efficient due to poor planning. Other factors include the negative perception that ambulances carry dead bodies, the demand for payment before patients are transported by ambulances, high cost of fuel, inadequate number of ambulances and the failure of emergency patients to pay the agreed hospital bills and services. The study recommends public education on the ambulance and emergency services to rid off false perceptions. Planning must also
\end{abstract}


explore how a district emergency fund can be set up to help alleviate the heavy financial burdens on patients and their families. Additionally, planning initiatives must promote the safety of accident and emergency victims by increasing the fleet of ambulance and emergency vehicles, improving upon the telephone and communication facilities and the training of more ambulance and health staff.

Keywords: Ambulance, Emergency Services, Healthcare, Planning, Ghana

\section{INTRODUCTION}

Healthcare is a service that is provided to individuals and communities by health service providers for the purpose of promoting health (WHO, 2004). The consensus among health Planners and many governments is that, healthcare is defined as the means for the achievement of health, as in the care, services or supplies related to the mental or physical health of an individual (U.S.A. Congress, 1996). In Ghana, healthcare to the Ministry of Health $(\mathrm{MoH})$ connotes the provision of quality, affordable and accessible health services delivered in a humane, efficient and effective manner by health professionals to improve the health status of Ghanaians ( $\mathrm{MoH}, 2014)$. For the purposes of this study, healthcare is defined as the treatment and management of illness, which can result in the deterioration of the physical and mental well-being of a person and can lead to death, with the help of medical and allied health professionals. There are health conditions that require immediate medical care and delays may result in dire consequences for a person's life. Such conditions are referred to as emergency situations (Kobusingye, Hyder, Bishai, Eduardo, Mock \& Joshipura, 2006).

Kobusingye et al. (2006) have noted that emergency medical conditions occur through a sudden injury, infection, birth and pregnancy related complications, or chemical imbalance in the body or mind. Health Planners and health service providers have indicated that minutes directly following emergency situations are often critical to saving patients' lives or minimizing the long term effects of the conditions. Consequently, the timeliness and level of expertise at which care is given are critical factors in increasing the survivability of patients in an emergency situation. Transporting patients from the location of an acute event to a health facility is a crucial element of emergency care therefore the lack of transportation is often the major barrier preventing patients from accessing emergency care in many developing countries. The transportation of victims during emergency situations is preferably made by ambulances. For Kobusingye et al. (2006), emergency transportation should be accessible at short notice suggesting that ambulance services are the best means for doing this. Ambulance services should have the equipment, expertise and experience of ambulance staff in emergency intervention, assessment, management and transport of patients in a variety of disaster environments (Gaston, 2007). 
Ambulance services are supposed to be the primary providers of a 24-hour response to medical and trauma related emergencies and interventions. These services can be by land or air referring to a vehicle or aircraft designed for the transportation of sick or injured people to, from or between places of medical treatment. In spite of the critical role ambulance services play in emergency healthcare provision, there are many challenges that undermine these services especially in the public sector of many poor countries. These difficulties include inadequate resources in terms of staff and equipment. Many of the available staff are poorly trained to handle emergency situations and many of the ambulance vehicles are ill-equipped with oxygen and basic facilities such as hand gloves (Osei-Ampofo, Oduro, Oteng, Zakariah, Jacquet, \& Donkor, 2012). In spite of these challenges, motor accidents that require emergency services are high in many parts of Africa (Norman, Matzopoulus, Groenewald \& Bradshaw, 2007; Statistics South Africa, 2009). For example, in South Africa, high rates of motor accidents and trauma have overstretched the state emergency services making the private sector a very important player in offering rapid response emergency services to augment efforts made by the state (Norman et. al., 2007).

Inefficient ambulance and emergency service leads to preventable deaths and disabilities. It is estimated that 800 women around the world die daily from preventable causes related to pregnancy and childbirth (WHO, 2012). As much as 99 percent of all maternal deaths occur in developing countries where emergency care is often lacking. More than half of these deaths occur in sub-Saharan Africa (WHO, 2012). It is estimated that 15 percent of all pregnant women experience a potentially life-threatening condition and will need emergency care (Kobusingye et al., 2006). Approximately 5.8 million people worldwide die annually as a result of injuries which accounts for 10 percent of the world's deaths. Nearly one third of the 5.8 million deaths from injuries are the result of violence and nearly one quarter are the result of road traffic crashes (WHO, 2010). This could be averted with the help of timely and efficient ambulance service and emergency care.

To enhance emergency medical service, the adoption of emergency management has been proposed. Emergency management encompasses four phases namely mitigation, preparedness, response and recovery. Mitigation deals with preventing disasters or taking steps to lessen the impact of unavoidable disasters. Preparedness includes all actions taken before the crisis occurs. This requires that emergency plans are developed, personnel at all levels and in all sectors are trained, identifying available resources which can be tapped during a disaster and communities at risk are educated and that these measures are monitored and evaluated regularly. Response is taking immediate action upon the occurrence of a disaster or emergency. Recovery, deals with taking the relevant actions to ensure safe return of victims to normal (WHO, 2007; Hanus, 2012).

In Ghana, cases requiring emergency medical services do not appear to have received adequate policy attention by governments since independence. Accident cases recorded over the years, suggest the various governments have left this very important sector of health in a neglected state (Amponsah, Amoako, Darkwah \& Agyeman, 2011). In 
Ghana medical emergencies usually result from road traffic accidents, during which victims of such accidents require urgent attention by stabilizing the conditions on the spot by paramedics and ambulance services. This needs to be followed by immediate transportation of the patient to the nearest health facility. A report by the Ghana Health Service (2012) revealed that Ghana recorded 1,022 maternal deaths in 2011. Over 60 percent of these deaths were as a result of unavailable ambulance service to transport women in labour to the appropriate medical facility (Ghana Maternal Health Survey, 2007). The conditions leading to maternal deaths can be addressed by appropriate and timely emergency care of which ambulance services play an important role.

The medical emergencies and tragedies that have occurred over the years have strongly highlighted the need for Ghana to initiate an emergency medical service. In 1999 the government emphasized the urgent demand for ambulance services as part of the emergency response system (Ministry of Health, 2008). The ill-preparedness of the country was made clear when the Accra sports stadium disaster occurred in 2000 in which nearly 130 people lost their lives (Ministry of Health, 2008). The stadium disaster pushed the Ministry of Health in collaboration with the Ministry of Interior to establish the seven pilot ambulance stations in 2004. This later became the National Ambulance Service (NAS) (MoH, 2008). The NAS aims at providing accessible 24-hour ambulance service nationwide through its own ambulance service and by collaborating with other service providers such as the Ghana National Fire Service and other hospital-based ambulances ( $\mathrm{MoH}, 2008)$. The presence of the NAS is now felt in every district. Currently, ambulance services make a huge range of unmeasured contributions to patient outcomes in emergency situations. These include the minimisation of clinical harm; the early defibrillation in sudden cardiac arrest; the early restoration of vital organ, perfusion in major trauma and the rapid transportation of the time critical patient to definitive care (see Pascoe \& Lynch, 2007).

Although there is literature attributing increased mortality to the lack of effective ambulance and emergency services in developing countries such as Ghana, the planning of such services has not received critical scholarly attention. This is particularly so in Ghana where there is lack of long term national health plan and the country is bedeviled with the lack of continuity in health planning by successive governments.

\section{CONTEXT AND METHODOLOGY}

Bibiani-Anhwiaso-Bekwai District is among the 22 districts of the Western Region. It is found in the North-Eastern part of the Western Region of Ghana. It has a surface area of approximately $873 \mathrm{~km}$ square with Bibiani as the District capital. It is bordered to the North by the Atwima Nwabiagya District in the Ashanti Region, to the West by Sefwi Wiawso District, to the South by Wassa Amenfi District and to the East by the Upper Denkyira District in the Central Region and Amansie East District in the Ashanti Region (BABDA, 2010) (see Figure 1). 


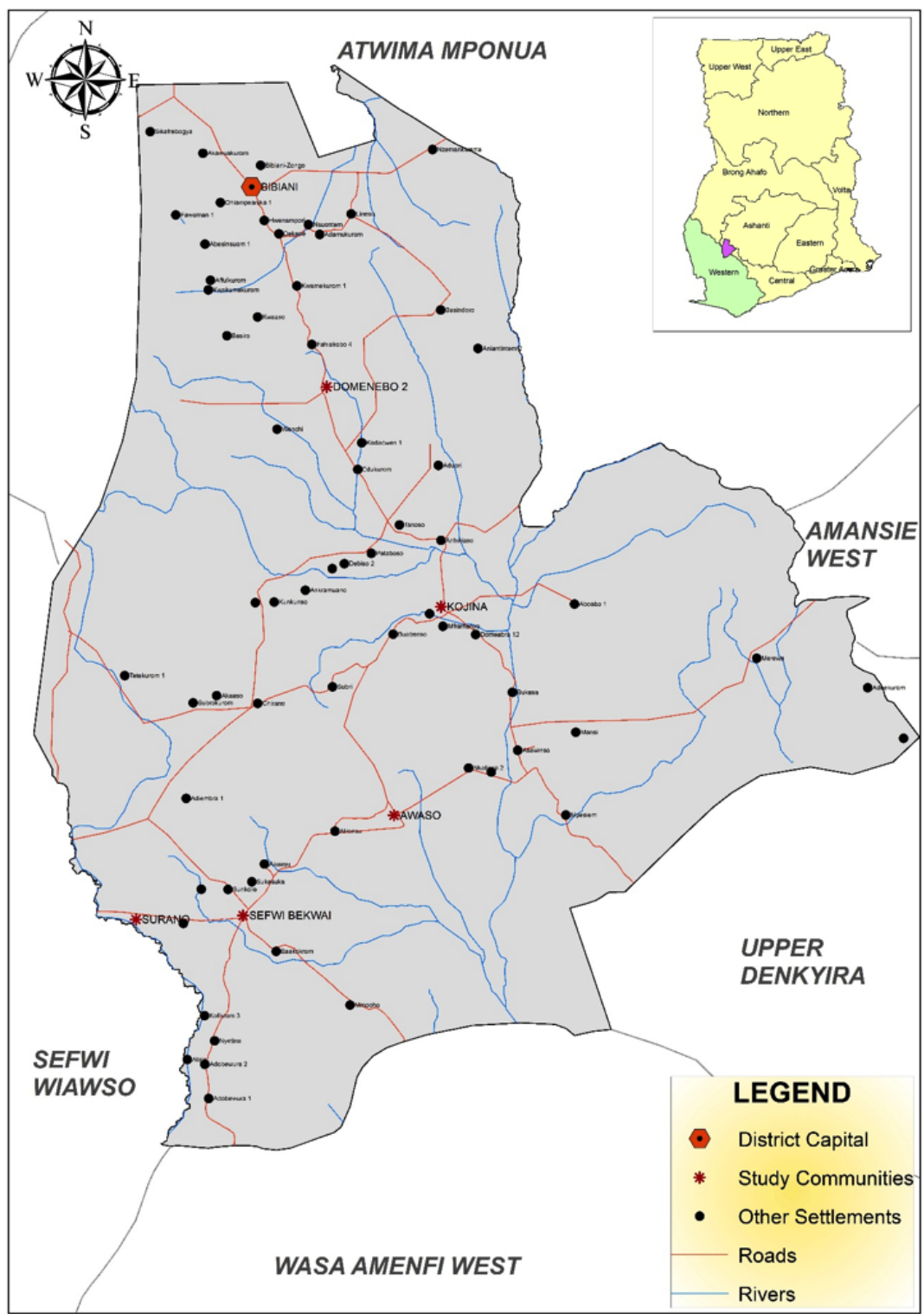

Figure 1: Map of Bibiani-Anhwiaso-Bekwai District

Source: Base map of Ghana Districts, 2007 
The District has a total of $309.3 \mathrm{~km}$ length of roads and about 80 percent of all the roads are feeder roads and less than 10 percent of these are motorable all-year-round. The District has a total population of 123,272 (Ghana Statistical Service, 2012; BABDA, 2010). The District is essentially rural with over 65 percent of the inhabitants engaged in small-scale farming and about 20 percent engaged in petty trading. Out of the 101 major settlements, there are only three urban centres constituting 37 percent of the total population (Donkor, 2011). The District Directorate of Health manages and coordinates health delivery in areas of both curative and preventive healthcare. These services are delivered at community, sub-district and district levels. Emergencies are mostly catered for at the District hospital in Bibiani which is the only public hospital, with complications referred to the Komfo Anokye Teaching Hospital in Kumasi which is $88 \mathrm{~km}$ away. The major means of transport in the District is by road.

The hospitals that offer emergency ambulance service to the general public are the Bibiani District Hospital and the Divine Love hospital which is privately owned but is National Health Insurance Scheme accredited. There are two privately owned hospitals in the District that belong to mining companies and these hospitals provide emergency ambulance services to miners and relatives of miners. The District hospital follows a planned preventive maintenance approach for maintaining the ambulance while the Divine Love hospital maintains its ambulance as and when the need arises. The ambulance service in both hospitals is financed by both the hospital and clients. Clients are made to pay for what is referred to as fuel fee, which is used to fuel the ambulance.

The NAS has Emergency Medical Technicians (EMTs) who provide paramedical service to emergency victims. When an emergency victim is picked up by the ambulance the EMTs on board complete a form known as the National Ambulance Service pre-hospital report form which contains personal information about the patient and information about the medical condition of the patient. This form is presented to the hospital on arrival and it gives first-hand information to health personnel which aid them in administering treatment to the patient. The pre-hospital sheet has a component which is used to check equipment in the ambulance to make sure the equipment is in their best shape to respond to emergencies. The service operates a preplanned maintenance schedule for vehicle maintenance, which is tendered by a group of engineers called Comet Engineering Company. The maintenance schedule is arranged by Comet Engineering Company and communicated to the district office; representatives of Comet Engineering Company go around to various ambulance stations to service the vehicles.

Five settlements were randomly selected along the Bibiani-Surano main road for the study. These are Surano, Sefwi Bekwai, Kojina, Dominebo and Awaso (refer to Figure 1). In each of these settlements, 20 residents who had had the need for ambulance services in the past ten years were selected using the snowball technique for interviews conducted in the local language using questionnaires. The questions covered how residents perceived the ambulance and emergency services, the state of these services, contribution of ambulance and emergency service to healthcare, factors affecting the performance of the service 
and the way forward for planning an efficient and reliable ambulance and emergency service in the district. In addition to the interviews with residents, discussions were held with health officers in the Bibiani Government Hospital, the Divine Love Hospital, the Noble Gold Company Hospital, the District office of the NAS and 20 taxi drivers who ply the selected road. These health facilities were selected on the basis that they operated ambulance services. The NAS was also chosen because it is the main public institution mandated to provide emergency ambulance. Findings from these discussions were used to validate the data that were obtained from the residents. Although many motor accidents are not reported to the police, available data from the Western Regional office of the Ghana Police Service was obtained to support what the residents and health staff provided.

\section{FINDINGS AND DISCUSSIONS}

\section{Emergency Health Situation}

Four kinds of emergency situations were recorded in the District over the past decade. These were motor vehicle accidents, pregnancy and birth related complications, snake bites and excessive vomiting (see Table 1). Motor traffic accidents topped with 40 percent out of the total of 790 reported cases over the ten year period that required emergency and ambulance service to be transported to hospitals in Bibiani. This was followed by pregnancy and birth related complications (32 percent). The lowest is excessive vomiting (13 percent). Discussions with hospital staff, vehicle operators and residents in the selected communities revealed that irresponsible and reckless driving were common in the District. The issue of reckless driving in this District may not be anything new as this is common throughout the country (see Jasmine, 2013; Makama, 2011), what may be unique is the number of cases recorded over ten year period. In all the cases of emergency, very high proportions of deaths were recorded during the time that ambulance services were being sought and in some cases, death occurring in the process of transporting accident victims to the nearest health facility. According to the Table 1, 47 percent of deaths were recorded out of the motor accident cases. The rest are 72 percent (pregnancy and birth related cases), 42 percent (snake bites) and 6o percent (excessive vomiting). 
Table 1: Emergency situations to hospitals between 2003 and 2014

\begin{tabular}{|l|l|l|l|l|}
\hline Condition & $\begin{array}{l}\text { No of cases } \\
\text { recorded }\end{array}$ & $\begin{array}{l}\text { Percentage } \\
\text { of the total } \\
\text { number }\end{array}$ & $\begin{array}{l}\text { Number of deaths } \\
\text { in the course of } \\
\text { being transported } \\
\text { to hospital }\end{array}$ & $\begin{array}{l}\text { Percentage } \\
\text { of number of } \\
\text { deaths }\end{array}$ \\
\hline $\begin{array}{l}\text { Motor traffic } \\
\text { accidents }\end{array}$ & 320 & 40 & 150 & 47 \\
\hline $\begin{array}{l}\text { Pregnancy and } \\
\text { birth related } \\
\text { complications }\end{array}$ & 250 & 32 & 180 & 72 \\
\hline Snake bites & 120 & 15 & 50 & 42 \\
\hline $\begin{array}{l}\text { Excessive } \\
\text { vomiting }\end{array}$ & 100 & 13 & 60 & 60 \\
\hline Total & 790 & 100 & 440 & 56 \\
\hline
\end{tabular}

Source: Field survey, May 2014

Among the reasons given by the residents and corroborated by health staff were that the ambulance arrived too late; ambulance could not be reached and unprofessional handling of accident victims by both ambulance staff and onlookers who would like to offer genuine help. The non-functioning and non-connectivity of many of the telecommunication services were blamed for instances when efforts to reach the ambulance services were frustrated by non-connectivity or telephone calls not going through.

The need for professional handling of accident victims is adequately documented (see WHO, 2004; Gopalakrishnan, 2012). Although the onlookers will like to offer genuine help, their inexperience can complicate matters and worsen the plight of accident victims. In addition, reliable telephone and communication systems are critical ingredients that explain success stories of ambulance and emergency services and healthcare delivery in many developing countries (see WHO, 2011; Curtis \& Ramsden, 2011).

\section{Conditions and Means of Transporting Emergency Cases to Health Facilities}

The need for effective planning of ambulance and emergency service in planning healthcare delivery at the District and rural community level was evident in the findings around the means of transporting patients needing emergency care to health facilities. The study revealed that only 10 percent of motor accident victims were transported to health facilities by the ambulance service. In the case of pregnancy and birth related cases, it was five percent. None of the snake-bite victims and residents who suffered from severe vomiting used ambulance service (see Table 2). 
Table 2: Emergency situations and means of transportation to hospitals

\begin{tabular}{|c|c|c|c|c|c|c|}
\hline \multirow[t]{2}{*}{ Condition } & \multirow{2}{*}{$\begin{array}{l}\text { No of cases } \\
\text { recorded }\end{array}$} & \multicolumn{5}{|c|}{ Means of Transport } \\
\hline & & Taxi & $\begin{array}{l}\text { Private } \\
\text { Vehicle }\end{array}$ & $\begin{array}{l}\text { Carried } \\
\text { on foot }\end{array}$ & Ambulance & $\begin{array}{l}\text { Total } \\
(\%)\end{array}$ \\
\hline $\begin{array}{l}\text { Motor traffic } \\
\text { accidents }\end{array}$ & 320 & $65 \%$ & $20 \%$ & $5 \%$ & $10 \%$ & 100 \\
\hline $\begin{array}{l}\text { Pregnancy and } \\
\text { birth related } \\
\text { complications }\end{array}$ & 250 & $60 \%$ & $30 \%$ & $5 \%$ & $5 \%$ & 100 \\
\hline Snake bites & 120 & $75 \%$ & $5 \%$ & $20 \%$ & - & 100 \\
\hline $\begin{array}{l}\text { Excessive } \\
\text { vomiting }\end{array}$ & 100 & $80 \%$ & - & $20 \%$ & - & 100 \\
\hline
\end{tabular}

Source: Field survey, May 2014

As much as 65 percent of accident victims were transported to health facilities in taxis. The figures are even high with residents who had been bitten by snakes (75 percent) and those vomiting (8o percent). According to the discussions with health officers and the community residents, over 80 percent of the taxis were rickety in very poor conditions. The conditions of the taxis can complicate matters if onlookers with no experience attempt to transport accident victims. This might explain the high causes of deaths that were recorded as noted by one of the health staff that:

"About 90 percent of all the taxis on our roads are old and in very bad conditions. Although the drivers have good intentions and genuine desire to help, their vehicles are not designed for such purposes so their good intentions end up creating more difficulties as many accident victims die while being transported in these taxis" (High profile health officer, Bibiani)

Results from all the taxi drivers interviewed corroborated these claims by this health officer. According to the taxi drivers, although they are aware that their taxis are not designed to do this, they cannot help than to assist to get accident and emergency victims to health facilities especially so when ambulance vehicles delay in arriving or are not available at all.

\section{Reliability of Services and Handling of Accident Victims}

In Table 3, the views of residents and taxi drivers about the ambulance service in the District were sought. Forty-one percent of respondents rated the service as 'satisfactory'. According to these respondents, the few ambulance vehicles worked within the numerous 
challenges to save lives and their efforts need to be acknowledged. For thirty-one percent of the respondents, ambulance services were 'bad'. The explanations for this rating were that hospitals made patients to pay for the fuel cost for the ambulance and ambulance vehicles developing mechanical faults while patients were being transported resulting in deaths. Over 50 percent of these respondents who lived outside the District capital indicated that they have been left out of the ambulance services. Their claim was that ambulances refuse to go beyond the District capital (Bibiani) and as a consequence they could not be attended to in emergency conditions. For example, the head of a household that had lost a household member through this process indicated that:

"Those of us who live outside Bibiani are not factored into the ambulance and emergence services. Perhaps it is because of the bad nature of our roads. Although accident and emergency cases are common in this area, there are not ambulance services" (A resident in Kojina).

These views partly explain the rating of these services as 'bad'. Only twenty-eight percent of the respondents rated the service as 'very good'. In their view, ambulance service was available on accident spot when needed.

Table 3: Perception of the public on ambulance service in the district

\begin{tabular}{|l|l|l|}
\hline Perception & Number & Percentage of total \\
\hline Verygood & 34 & 28 \\
\hline Satisfactory & 49 & 41 \\
\hline Bad & 37 & 31 \\
\hline Total & 120 & 100 \\
\hline
\end{tabular}

Source: Field survey, May 2014

These claims about the ratings of ambulance services were supported by what we found about practical challenges of ambulance and emergency service. These are discussed next.

\section{CHALLENGES OF AMBULANCE AND EMERGENCY SERVICES}

\section{Poor Road Conditions}

Interviews with about half of the drivers of the ambulance service, high profile staff at the various health facilities and residents revealed that the poor conditions of roads in the District heavily constrained the work of ambulance services. Many sections of the roads have developed very wide pot-holes while other sections have deteriorated from heavy erosion and the lack of maintenance. Consequently, delays were found to be common as the expected speed limit of $200 \mathrm{~km} / \mathrm{hr}$ is reduced to about $50 \mathrm{~km} / \mathrm{hr}$. This low speed cannot 
be good enough for lives to be saved. The bad road conditions were also blamed for the mechanical faults that develop when patients are being transported. The study also found that there were instances when ambulances got involved in accidents while transporting emergency cases to the hospital. According to the records at the District Police Office, these accidents occur as a result of the poor road conditions. Evidence on the poor nature of roads is supported by the District Assembly records showing 52.5 percent of roads in the District were in a deplorable condition (BABDA, 2010).

\section{Misconceptions and Superstition about Ambulance Services}

The study revealed that 70 percent of respondents had the belief that ambulances were for carrying corpses. As a result of this perception, some residents of the District refused to engage the services of an ambulance thinking that on-lookers would think it is a dead relative being carried away. Many residents also prevent ambulance vehicles from parking in front of their residence as other people might see this and perceive it to be an impending funeral in the family. This perception contributed to many families rather opting for taxis in times of emergencies further undermining the work of the ambulance service.

Although this perception appears odd, the increase in hearse services operating as if they are ambulances for the transportation of bodies from morgues across the country particularly during the weekends in recent times tends to give credence to this.

\section{Inadequate Support from Other Road Users - Vehicle Operators and Pedestrians}

A major concern of ambulance operators was that vehicle operators and pedestrians did not adequately cooperate with them. This frustration can be seen from how one of the ambulance drivers put it:

"Many transport operators ignore the siren and refuse to make way for the ambulance. This causes a lot of delays making the ambulance to reach the accident spot and health facility too late. In spite of the sirens and flashing lights, many motorists just pretend to be unaware of the situation to give way."

Again in the cause of the journey, ambulances are delayed by congested roads particularly at the time of the day when most workers are coming back home from work. Another driver noted: "the congestion results in a lot of pedestrian crashes. It is therefore becoming increasingly difficult for ambulances to make it to emergencies." For the emergency service, every second counts. Delaying the passage of an ambulance can mean a matter of life and death. Many people get anxious or simply do not adhere to the traffic rules on the road for approaching emergency vehicles. Cooperation of all road users on 
the roadway is essential. The lack of cooperation as presented above is either because the public are not acquainted with what to do, or unwilling to cooperate.

\section{Rising Cost of Fuel}

It was revealed that the rising cost of ambulances makes operating the ambulance service costly and this has informed the payment of ambulance fuel fee by patients transported by the ambulance. A high profile health officer of Bibiani Hospital intimated:

"We ask families of accident victims to pay for the fuel after we have brought the person here and stabilized the condition. Sometimes we ask that the payment is done before we transport the person to the hospital and we do this if the condition is not life threatening such as women in labour. We do this because often time families refuse to pay after we have rendered the service."

Fuel price increases are not uncommon in Ghana. The prices of petroleum products have ever been increasing in the country. The hike in petroleum products poses a challenge to the national economy as well as the operators of ambulance service who will have to contend with an additional running cost to their operations. The price increases have a ripple effect on the cost of doing operations and consequently, the ability of the service to absorb its maintenance cost and continue to run a no-user-fee service especially for emergency service in hospitals. High fuel cost also increases maintenance cost and the cost of supplies for the ambulance.

\section{Inadequate Number of Ambulances}

The District is faced with inadequate ambulance fleet, which makes it difficult for the ambulance service to generally respond to emergency situations within the standard time of eight minutes. Altogether, public hospitals in the District and the private healthcare facilities had a total of three ambulance vehicles available. Due to frequent breakdowns, ambulances at the hospitals are mostly out of service. The NAS has only one ambulance and is therefore overwhelmed by the quantum of the workload which includes accompanying the fire tender to attend to distress calls; responding to accidents and other emergency medical conditions; and transporting patients on referral to hospitals within the District or the Komfo Anokye Teaching Hospital. The result of this is that families find it more convenient to get the patient to the nearest hospital by a private vehicle or taxi, to avoid waiting for an ambulance which may not arrive or may take a very long time to arrive.

\section{Failure to Settle Hospital Bills}

Hospitals in the District are faced with the problem of failure to pay hospital bills by patients. We found that in most cases, patients had to be detained especially patients 
from the emergency and accident units. The study found that some 'hit and run' accident victims who had no hope of settling their medical bills also escaped in their stiches. About 80 percent of the residents interviewed admitted to facing financial difficulties such that they cannot afford life's basic necessities and more so to settle hospital bills. The refusal of patients and families of patients to pay the agreed bill was found to limit the capacity of the health facilities and ambulance services to deliver this important service. An ambulance staff noted:

"Some patients are brought in under very critical conditions which require immediate attention. Under these circumstances the hospitals agree to treat patients while patients and their families make payments after treatment. However, when the patients get better they leave the hospital without paying for the cost of treatment."

Discussions with senior police officers at the Bibiani Police station established that the majority of patients who refuse to pay hospital bills are those who have emergency conditions and are brought to the hospital under serious conditions.

A very influential community leader in Bibiani added:

"Hospital staff resort to asking relatives of accident victims to fuel the vehicles. This sometimes leads to conflicts with hospital officials. There are several instances of failure by accident victims and their families to reimburse the hospital after the ambulance has transported their relatives on referral."

The hospitals that were interviewed have resolved for this payment to be made before patients are transported. This situation can lead to delays occurring in the conveyance of emergency patients on referral. This could compromise the lives of patients.

\section{Inadequate and Poorly Trained Accident and Emergency Health Staff}

The number of health workers in the District was 219 and the number of Emergency Medical Technicians was 7, including the EMT leader. From the 2010 Population and Housing census report, the population of the District is 123,727 people. This results in an EMT/ population ratio of 1: 17675 . On the other hand, the health worker/population ratio is 1:564. This staffing situation in the District is woefully inadequate for the smooth running of emergency services. The District office of the NAS complained that they have not been able to carry out education on the ambulance and emergency service because they lack the staff.

This staffing situation shows that emergency healthcare service in the District has a weak capacity to provide meaningful emergency services as a result of inadequate staff. The training of government ambulance workers in Ghana is to the level of an Emergency Medical Technician (EMT). This level of training enables EMTs to be able 
to provide only basic life support which is a rudimentary service. EMTs cannot provide Advance Cardiac Life Support which as the name implies is an advanced level of prehospital and inter-hospital care which includes cardiac monitoring, cardiac defibrillation, electrocardiography, intravenous therapy, administration of medications, drugs and solutions, use of adjunctive medical devices and trauma care. Emergency Medical Technicians are required to work closely with other healthcare professionals and emergency services and are therefore required to be highly trained and skilled in all aspects of pre-hospital care ranging from crash injuries to cardiac arrests. There is therefore the need to upgrade the skills of emergency medical technicians at the District in order to operate the advanced life support equipment. Generally the country lacks emergency medical nurses. Injured persons or victims of medical, surgical, or obstetric emergencies have to deal with emergency care centers that do not have specially trained health workers. This results in delays between diagnosis and treatment leading to the loss of lives. The importance of making health workers with appropriate skills available to handle emergency cases cannot be overemphasized as it determines the success of emergency care.

\section{CONCLUSION AND RECOMMENDATIONS}

Emergency medical services are public services that provide the first line of response to urgent healthcare needs within a community. As a result emergency care needs to be projected as an integral component of planning public health systems. The planning of emergency care must be approached from a systems point of view with interdependent components. These include pre-hospital care, transportation, and hospital care. Local hospitals or facilities that treat emergencies (often district hospitals) are best positioned to coordinate these services as an uninterrupted unit. From this a plan may be drawn that outlines an immediate response structure and a secondary, health-centric response framework. In addition, the plan may include non - traditional emergency response partners.

The wrong perception held by the residents in the District can be addressed through the planning of effective and comprehensive education on the operations and activities of the ambulance service. This must be incorporated into the Medium Term Development Plans of the District Assembly and coordinated by the District office of the NAS across the District. Health plans and strategies should make provision for programmes for residents in the District to be taught basic first aid tips to be able to offer help when there is any emergency situation.

The District Assembly must set aside funds in the annual plans and budgets to support emergency and ambulance services. Although emergencies are covered under the health insurance scheme, emergency transportation must also be absorbed by the National Health Insurance Scheme. Public funding for emergency health is more sustainable; however private funding in the form of trusts, donations, and fundraising activities 
can augment the public funds. In exploring the availability of funds locally the National Ambulance Service must consider establishing a national disaster preparedness fund. An emergency fund can also be set aside as a portion of the national road safety fund, and mandatory car insurance which can help fund projects for building local capacities for emergency and disaster response.

There is the need for communication systems that would allow for the rapid flow of information during an emergency. The National Ambulance Service number 193 currently works from land lines and cell phones, however it does not work in places with weak or limited network coverage. In a mostly rural district cellular telephones offer households that opportunity to access ambulances during emergency situation but cell phone dead spots and the challenge of getting good network coverage is a problem. A coordinated effort between the National Ambulance Service and telecommunication providers to ensure that the service number can still be reached even when there is insufficient network coverage must be promoted.

The training of additional ambulance workers and emergency health nurses is needed. Paramedics should be given adequate training to effectively and safely handle accident and emergency patients.

The fleet of ambulance vehicles needs to be increased. Healthcare plans should aim at seeking the support of NGOs and other philanthropists to come on board to help acquire more ambulances. Each of the three circuits in the Bibiani-Anhwiaso-Bekwai District should develop a comprehensive ambulance and emergency plan with which to look for funding to support this important service.

\section{References}

Amponsah, S. K., Amoako G., Darkwah, K. F. and Agyeman, E. (2011). Location of ambulance emergency medical service in the Kumasi Metropolis, Ghana. African Journal of Mathematics and Computer Science Research., 4(1), pp.18-26.

Bibiani-Anhwiaso-Bekwai District Assembly (BABDA). 2010). Medium term developmentplan ofBibiani-Anhwiaso-Bekwai District (2010-2013). Bibiani: BibianiAnhwiaso Bekwai District Assembly.

Curtis, K. and Ramsden, C. (2011). Emergency and trauma care for nurses and paramedics. Elsevier Australia, North South Wales-Australia.

Donkor, J. A. (2011). The status of information, education and communication on prenatal care and skilled delivery: The case of Bibiani-Anhwiaso-Bekwai District, Ghana.Unpublished MSc Thesis, Kwame Nkrumah University of Science and Technology, Kumasi, Ghana. 
Gaston, c. (2007). How an ambulance service can contribute to the health care continuum in health. Center for Policy Development (CPD) InSight (2008-11), InSightedition Prescriptions for a Healthy Australia. Available at: http://cpd.org.au. Accessed: $10^{\text {th }}$ February 2013.

Ghana Districts (2007). Base Map of Bibiani-Anhwiaso-Bekwai District. Available at: http:// www.ghanadistrict.com. Accessed: $13^{\text {th }}$ February 2013.

Ghana Statistical Service. (2012). 2010 Population and Housing Census of Ghana: Population by District, Sex and Type of Locality, Western Region. Accra: GhanaStatistical Service.

Ghana Statistical Service. Ghana Health Service (GHS), and Macro International. (2009). Ghana Maternal Health Survey 2007. Calverton, Maryland, USA: GSS, GHS and Macro International.

Gopalakrishnan, S. (2012). A public health perspective of road traffic accidents. Journal of Family Medicine and Primary Care. 1(2), pp. 144-150.

Hanus, R. (2012). The four phases of emergency management. The Preparedness Podcast. Available at: http://www.thepreparednesspodcast.com. Accessed: $13^{\text {th }}$ February 2013.

Jasmine, A. (2013). Road Accidents; Reckless Driving a major cause. Graphic Online. Available at: www.graphic.com.gh. Accessed: $25^{\text {th }}$ November 2014.

Kobusingye, O. C., Hyder, A. A., Bishai, D., Eduardo, R. H., Mock, C. and Joshipura, M. (2006). Emergency medical services. Disease Control Priorities in Developing Countries. 2(68), pp. 626-628.

Makama, K. (2011, 23 September). Ghana suffers the carnage of road accidents. Available at: www.ghanaweb.com. Accessed: $25^{\text {th }}$ November 2014.

Ministry of Health (2008). National Ambulance Service (NAS). Policy Briefing Paper. Accra: National Ambulance Service.

Ministry of Health. (2012). Functions and roles. Available at: http://www.mohghana.org. Accessed: $19^{\text {th }}$ November 2014.

Norman, R., Matzopoulus, R., Groenewald, P. and Bradshaw, D. (2007). The high burden of Injuries in South Africa. Bulleting of World Health Organisation, 85(9), pp. 649-732.

Osei-Ampofo, M., Oduro, G., Oteng, R., Zakariah, A., Jacquet, G. and Donkor, P. (2012). The evolution and current state of emergency care in Ghana. African Journal of Emergency Medicine. 3(2), pp. 52-58. 
Pascoe, S. and Lynch, J. (2007). Adult trauma clinical practice guidelines, management of hypovolaemic shock in the trauma patient. NSW Institute of Trauma and Injury Management, New South Wales.

Statistics South Africa (2009). Road traffic accident deaths in South Africa, 2001-2006: Evidence from death notification. Pretoria: Statistics South Africa.

USA Congress, Health Insurance Portability and Accountability Act of 1996. Washington D.C: U.S Congress.

World Health Organization (2004). World report on road traffic injury prevention: Summary. World Health Organization Publications, Geneva-Switzerland.

World Health Organisation (WHO), (2007). Risk reduction and Emergency Preparedness: WHO six year strategy for the health sector and community development. Geneva, Switzerland: World Health Organisation.

World Health Organisation (WHO), (2010). Injuries and Violence: the facts. Geneva, Switzerland: WHO.

World Health Organization (2011). Hospital emergency response checklist: An all- hazards tool for hospital administrators and emergency managers. WHO Regional Office for Europe, Copenhagen, Denmark.

World Health Organisation. (2012). Maternal Mortality: media centre, fact sheet No. 348 . Geneva, Switzerland: WHO. 